\title{
Atypical benign paroxysmal positional vertigo in a case of acoustic neuroma
}

\begin{abstract}
We present the case of a patient with episodes of dizziness triggered by postural changes, with findings atypical to neurotological examination, and whose final diagnosis was an acoustic neuroma.
\end{abstract}

Keywords: acoustic neuroma, benign paroxysmal positional vertigo
Volume 8 Issue 5 - 2017

\author{
Sergio Carmona,' Ray Salazar, ${ }^{2}$ Guillermo \\ Zalazar' \\ 'Department of Neurologist, Fundación San Lucas para la \\ Neurociencia, Argentina \\ ${ }^{2}$ Department of Otorhinolaringologist, Clínica San Felipe, Perú \\ Correspondence: Sergio Carmona Department of \\ Neurologist Santa Fe Argentina, Tel +54341515744I, \\ Email sergiocarmona57@gmail.com \\ Received: September 05, 2016 | Published: September 20, \\ 2017
}

Abbreviations: YO, year old; BPPV, benign paroxysmal positional vertigo; ENT, ear, nose and throat; $\mathrm{HC}$, horizontal canal

\section{Introduction}

Benign paroxysmal positional vertigo (BPPV) is a disorder arising from a problem in the inner ear. Symptoms are recurrent and brief periods of vertigo with movement, that is, of a spinning sensation upon changes in the position of the head. ${ }^{1}$ Unfortunately, not all positional vertigos are benign. ${ }^{2}$ Symptoms similar to those of BPPV can be caused by diseases that affect the central nervous system. We must define the criteria that allow us to suspect the possibility of a cerebral origin in a patient with symptoms of positional vertigo:

i. Presence of other signs or symptoms of neurological disorder

ii. Presence of nystagmus without dizziness in positional tests

iii. Atypical nystagmus direction

iv. Poor response to therapeutic manoeuvres

v. Frequent recurrence of symptoms ${ }^{2}$

\section{Case presentation}

We hereby present the case of a female patient, 62 y.o., who consulted other Otolaryngology services 3 months before her first visit due to vertigo that lasted seconds upon head movements, especially when getting up or lying down; she is diagnosed with BPPV in the right ear with no specification as to the canal; maneuvers are performed which result in partial improvement. Two months ago she experienced a more intense vertigo attack that also lasted seconds, and the exam performed at our Service detected it in Mc Clure position: Short latency and geotropic horizontal nystagmus on both sides were observed, which lasted during 10minutes on the left side (where the patient reported more discomfort) and was intense in the right ear and lasted 6-7minutes.

Geotropic horizontal positional nystagmus with latency was observed, more prolongued on the left side, where we recorded 10 minute duration and showed more symptomatology and was more intense on the right side, where we recorded 7 minute duration (Video $1 \& 2)$.
The patient has a history of diabetes type II and hypotiroidism. Her ENT exam was normal, and it only showed mild sensorineural and symmetric hearing loss in high frequencies with normal discrimination. Her neurologic exam was normal.

Gufoni repositioning maneuver was performed for BPPV of the right lateral canal (canalithiasis). She was asked to come back 72hours later and she then reported feeling better; Mc Clure maneuver was performed and the nystagmus still persisted with the same characteristics; Gufoni maneuver was performed for the second time and she was asked to come back again 72 hours later, no changes were observed; a posterior fossa and cerebellum MRI was requested with contrast and angio-resonance where a Neuroma of the eighth cranial pair of the right ear and a frontal falxmeningioma were observed (Figure 1). Patient's sign lasted few months, she was not operated. Patient's sign lasted few months, she did not undergo surgery.

\section{Discussion}

Benign paroxysmal positional vertigo is a common type of vertigo observed by otolaryngologists; however, intracranial tumors can mimic benign paroxysmal positional vertigo in their presentation. ${ }^{2}$ When the patients with positional vertigo present atypical signs presentation, nystagmus or response to the canalith repositioning maneuver a radiological investigation must be undertaken in every doubtful case. ${ }^{3}$

Though positional nystagmus has many of the more important clinical characteristics of the horizontal canal BPPV by canalithiasis - latency, geotropic direction and finally exhaustion - its prolongued duration to both sides and the lack of response to Gufoni maneuver, which has an evidence-based efficacy, ${ }^{4,5}$ guided us towards an atypical form of $\mathrm{HC}$ BPPV and thus we requested neuroimaging studies. ${ }^{6}$

The Gufoni maneuver ${ }^{7}$ illustrated is used to treat right-sided horizontal canal benign paroxysmal positional vertigo (BPPV) that is geotropic (A) or apogeotropic (B) in nature. Numbers 1-3 depict the sequential steps in each maneuver. For geotropic nystagmus of lateral canal BPPV, the patient is taken from the sitting position to the straight side-lying position on the unaffected side (left in this case) and held in that position during 1minute (Figure 2). 


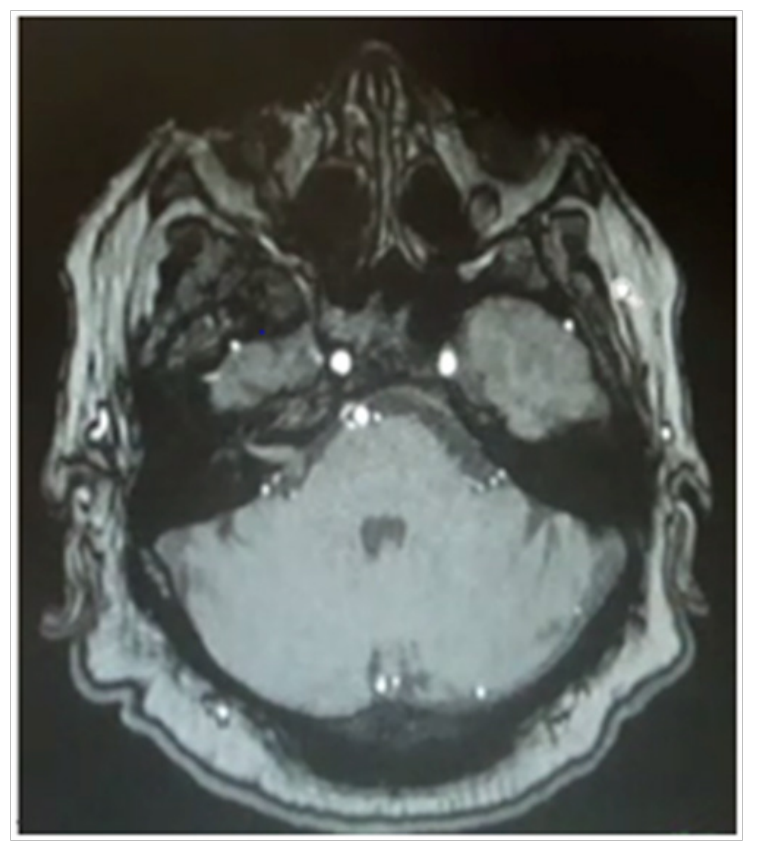

Figure I TI-weighted RMI with gadolinium where neuroma is observed at the right cerebellar angle.

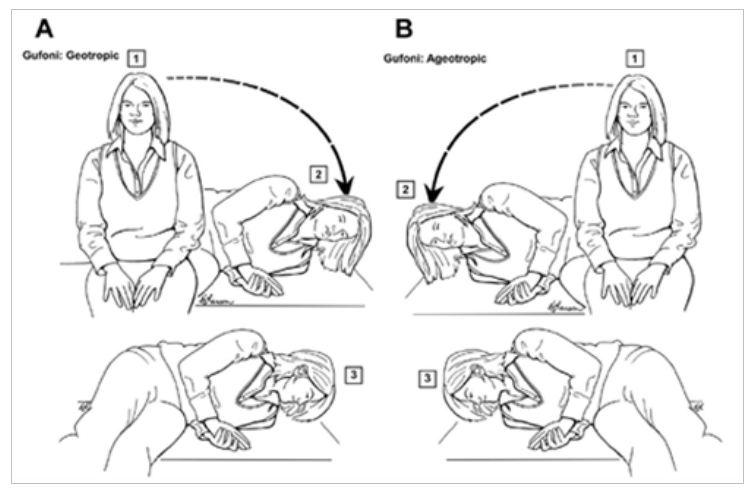

Figure 2 The Gufoni maneuver7 illustrated is used to treat right-sided horizontal canal benign paroxysmal positional vertigo (BPPV) that is geotropic (A) or apogeotropic (B) in nature.

The patient's head is quickly turned toward the ground about $60^{\circ}$ and held in that position during 1 minute. The patient then sits up again with the head held toward the left shoulder until sitting upright again. For right horizontal canal BPPV with apogeotropic-type nystagmus, the patient is taken from the sitting position to the straight side-lying position on the unaffected side (right in this instance) during 1 minute. Then the patient's head is quickly turned $60^{\circ}$ toward the ground and held in the position during 1 minute.
The patient then sits up again, keeping the head held toward the right shoulder until fully upright. The presence of a right neuroma, where the nystagmus is more intense, may indicate compression as it cause, but it is hard to explain its change of direction and the absence of hyperventilation induced nystagmus.

Given the size of the tumor, there may be a dynamic compression on the vestibular nuclei which may generate variable information on the velocity storage mechanism or perhaps a true BPPV with an impaired velocity storage mechanism. ${ }^{8}$

The presence of atypical BPPV must be studied with imaging studies, in this case of acoustic neuroma, hearing was symmetric and the only key were the atypical signs of the BPPV as explained.

\section{Conflicts of interest}

Author declares there are no conflicts of interest.

\section{Acknowledgments}

None.

\section{Funding}

None.

\section{References}

1. Bhattacharyya N, Baugh RF, Orvidas L, et al. Clinical practice guideline: benign paroxysmal positional vertigo. Otolaryngology Head Neck Surg. 2008;139(5 Suppl 4):S47-S81.

2. Dunniway HM, Welling DB. Intracranial tumors mimicking benign paroxysmal positional vertigo. Otolaryngology Head Neck Surg. 1998;118(4):429-436.

3. De Stefano A, Kulamarva G, Dispenza F. Malignant paroxysmal positional vertigo. Auris Nasus Larynx. 2012;39(4):378-382.

4. Riggio F, Dispenza F, Gallina S, et al. Management of benign paroxysmal positional vertigo of lateral semicircular canal by Gufoni's manoeuvre. Am J Otolaryngol. 2009;30(2):106-111.

5. Kim JS, Oh SY, Lee SH, et al. Randomized clinical trial for apogeotropic horizontal canalbenign paroxysmal positional vertigo. Neurology. 2012;78(3):159-166.

6. Soto-Varela A, Rossi-Izquierd M, Sánchez-Sellero I, et al. Revised criteria for suspicion of non-benign positional vertigo. QJM . 2013;106(4):317-321.

7. Fife TD, Von Brevern M. Benign paroxysmal positional vertigo in the acute care s etting. Neurologic Clin. 2015;33(3):601-617.

8. Susan Herdman and Richard Clendaniel. Vestibular Rehabilitation $\left(4^{\circ}\right.$ edn). FA Davis Company, Philadelphia United States of America. 2014. 